funds on centres of research excellence, to allowing scientists to spend part of their working time doing voluntary teaching in schools (a practice recently adopted in France). Other suggestions are included in a series of responses to their case solicited from various prominent figures such as President Eisenhower's science adviser, James R. Killian, and Edwin H. Land of Polaroid camera fame. (Unfortunately most of these luminaries use the opportunity to present their own views on how science should or should not be run, rather than give detailed opinions on the ideas of the two principal authors.)

In the end, however, any arguments about the optimal strategy for science and technology which emphasize questions of internal structure, such as the relative weighting to be given to basic, "strategic" and applied research, without paying equal attention to the political logic of the external pressures which frequently determine this internal structure, inevitably appear idealistic, if not utopian. To argue, like Shapley and Roy, that American science is "lost at the frontier" and that science policy is "adrift", implies that a map and a rudder would answer the basic problems. But this raises the allimportant question of how (or whether) agreement will be secured on a single map - or whose hand will be allowed on the rudder. And it can be argued that one of the most important changes in American science policy over the past decade has been the increasing influence that private industry and the military have been able to exert over precisely these processes.

There has been a long tradition of members of the scientific community declaring a strong aversion to the untidiness of the procedures by which rudimentary political issues, including the control of the direction of science and technology, tend to be resolved in society. If only, it is often argued, the organization of science - and of society too - could be made more scientific, conflicts and inefficiencies would be eliminated and the whole enterprise would immediately become more productive.

Shapley and Roy clearly share such hopes. Their optimism is to be admired, and there are sectors of the research enterprise in the United States where their solutions are certainly appropriate. But their insistence on the supremacy of scientific management risks overlooking the extent to which the cracks currently appearing in the American research system can be read as symptoms - rather than causes - of broader economic and political conflicts. It also underestimates how far these latter factors need to be taken into account if a truly rational policy for science and technology is to be achieved.

David Dickson is the European correspondent for Science, based at Le Billehou, St Aubin, 91190 Gif-sur-Yvette, France, and author of The New Politics of Science (Pantheon, 1984).

\section{Truths of planetary evolution}

\section{S.R. Taylor}

The Geology of the Terrestrial Planets. By Michael H. Carr, R. S. Saunders, R. G. Strom and D. E. Wilhelms. NASA: 1984. Pp. 317. $\$ 16$ (North America), $\$ 20$ (elsewhere).

EVERY geologist should be familiar with the landscapes and geological processes of the Moon and nearby planets, if not on account of their inherent interest then because of the insight and perspective which they shed on terrestrial geology. The authors of this volume have all made signal contributions to planetary geology, clearing away in the process much of the preApollo confusion, and here provide an upto-date and readable summary of our present understanding of the subject. Those scientists who dismiss geological evidence as merely pictorial in nature would do well to read this book and perhaps discover that hard truths about planetary evolution do emerge from the study of landscapes. Even students of cosmology should be interested to learn that the radius of Mercury shrank by a kilometre or so about $4 \times 10^{9} \mathrm{yr}$ ago but, like the Moon, has remained static since that time, placing limitations on the variation of $G$ and causing disarray among proponents of expanding Earth hypotheses.

Many questions remain to be answered. Are the smooth plains of Mercury really analogous to lunar maria or are they ejecta blankets? The composition of Mercury is clearly distinct from that of the Moon, and the recent failure to confirm, by reflectance spectra, the presence of $\mathrm{Fe}^{2+}$ on the surface must arouse doubts about their volcanic nature. A further problem is whether heavily cratered surfaces, on Mercury and in the lunar highlands especially, are saturated with craters, or constitute a production population. In the latter case, we can read the history of the surface since accretion. The former possibility, that we see only the record of the closing stages of the great meteoritic bombardment, implies that the observed lunar highland surface is no older than 4.1 or $4.2 \times 10^{9} \mathrm{yr}$. This seems more likely to me. Equally contentious is the existence of the giant Procellarum basin, 3,200 km in diameter, which may underlie much of the visible face of the Moon. Wilhelms's overview of lunar multi-ring basin stratigraphy removes the basis for the once popular "lunar cataclysm" hypothesis. The nature of the Tharsis bulge on Mars, whether a plateau uplifted by internal forces, or constructed by volcanic flows, remains open, but evidence for the former presence of flowing water on Mars seems unequivocal. The surface of Venus is perhaps analogous to earliest Archaean times on the Earth. Evidence of granitic or other siliceous rocks, so typical of the continental crust of the Earth, appears to be minimal for Venus and the other planets; such rock types, familiar even to city dwellers as facings of buildings, may thus be uniquely terrestrial, a consequence of the abundance of liquid water.

The geological study of the terrestrial planets continues to flourish. More recent discoveries of many multi-ring basins on Mercury and the possibility that the lunar megaregolith is $25 \mathrm{~km}$ deep do not appear in the book, but it is nonetheless commendably up to date. Overall editorial control appears to have been satisfactorily light, so that the expertise and style of the individual authors (Strom on Mercury, Saunders and Carr on Venus, Carr on the Earth and Mars, and Wilhelms on the Moon) show through clearly.

Minor failings include an inadequate index of three pages (partly offset by a fourpage table of contents). References are given at the end of the book, by chapter, but a combined reference list would have been preferable. Don Wilhelms will be especially chagrined to find that his beautiful plates (C and D on pp. 202-205) of the palaeogeography of the Moon have been transposed. And the maps, 18 pages of them at the end of the book, are really too small; NASA, unconstrained by the limitations of commercial publishers, would have been better advised to have included their useful larger series of planetary maps in a pocket.

This is a valuable contribution to the literature dealing with the terrestrial planets. It provides an excellent basis for university courses in the geology of the terrestrial planets as well as solid reading for geologists involved in the subject.

S. R. Taylor is a Professorial Fellow in the Research School of Earth Sciences, Australian National University, Canberra ACT, Australia 2601.

\section{Chemical reference in English}

Two of the oldest and best known reference works for chemists, Beilstein Handbook of Organic Chemistry and Ullmann's Encyclopedia of Industrial Chemistry, published in German for 104 years and 71 years, respectively, are now appearing in English.

Beilstein consists of a main series and five supplementary series. Publication in English has started with Vols 17-27 (heterocycles) of the fifth supplementary series (EV) of the fourth edition, covering the literature from 1960 to 1979. Executive editor of the work as a whole is R. Luckenbach of the Beilstein Institut, publisher is Springer-Verlag.

Ullmann's in English is to be a 36-volume series - 28 "A" volumes (alphabetically arranged articles) and 8 " $\mathrm{B}$ " volumes (basic knowledge), to appear at the rate of three or four a year - and commenced with Vol. A1 of the fifth edition, Abrasives to Aluminum Oxide. Executive editor is W. Gerhartz and publisher is VCH. 